\title{
Editorial for the special issue on the molecular genetics of male infertility
}

\author{
Csilla Krausz $^{1}$
}

Published online: 18 December 2020

(c) The Author(s), under exclusive licence to Springer-Verlag GmbH, DE part of Springer Nature 2020

Male infertility is a common, multifactorial pathological condition affecting about $7 \%$ of the general population. It may manifest with various semen phenotypes which are, respectively, termed azoospermia (complete absence of spermatozoa in the ejaculate), oligozoospermia (reduced number of spermatozoa) and various qualitative defects which include reduced sperm motility (asthenozoospermia), morphology (teratozoospermia) or the combination of qualitative and quantitative defects (oligoasthenoteratozoospermia, OAT). Disturbances of the male reproductive function may derive from defects of the hypothalamus-pituitary-testicular axes, primary testicular dysfunction and post-testicular anomalies affecting the urogenital tract (Tournaye et al. 2017b). Genetic factors play a role in all these major etiological categories and some of them are tested as part of the routine diagnostic workup of infertile men (Krausz and Riera-Escamilla 2018). Karyotype anomalies (numerical or structural) constitute the "oldest" known genetic causes of azoospermia and oligozoospermia. The $\mathrm{Y}$ chromosomelinked AZoospermia Factor (AZF) deletions, causing severe oligo-or azoospermia, have been routinely screened for since the late 1990s, when molecular genetic tools became widely available (Vogt et al. 1996; Krausz et al. 2014). Although AZF deletions would fit into the topic of this Special Issue, the reader is referred to an extensive review on spermatogenic failure and the $\mathrm{Y}$ chromosome, published in another special issue of Human Genetics (Krausz and Casamonti 2017).

Human spermatogenesis takes approximately 72 days to be completed (Di Persio et al. 2017). During this long process, the activation of about 2000 protein-coding genes contributes to the genesis and maturation of millions of male

Csilla Krausz

csilla.krausz@unifi.it

1 Department of Experimental and Clinical Biomedical Sciences "Mario Serio", University of Florence, Florence, Italy gametes. It is, therefore, clear that the genetic landscape of male infertility is highly complex and research in this field requires specific approaches which are extensively discussed in this issue (Houston et al. 2021; Kasak and Laan 2021; Soraggi et al. 2021; Xavier et al. 2021). Androgenetics has gone through all the classic steps of molecular genetics, starting from Sanger sequencing followed by array-based technologies and finally Next Generation Sequencing (NGS)-based whole exome sequencing (WES). An overview of the impact of various technological developments on male infertility gene discovery over the last 50 years is presented by Xavier et al. (2021). It is worth noting that the SNP arraybased approach in the context of genome-wide association studies (GWAS) has turned out to be largely unsuccessful in discovering clinically relevant risk factors for male infertility (Krausz and Riera-Escamilla 2018). However, it can be postulated that common genomic variants may still act through a combined effect (polygenic model) as fine-tuners of spermatogenesis and can be responsible for mild forms of oligozoospermia. A completely different scenario can be envisaged for severe forms of spermatogenic impairment where rare, large-effect size mutations in single genes (Mendelian model) or in multiple genes (digenic or oligogenic model) are likely to play a major role. It is expected that, due to strong purifying selection against infertility-causing mutations, the frequency of each causal variant is very low and this may explain the extreme paucity of monogenic causes in the pre-NGS era. A major breakthrough in discovering and validating disease-causing genes derives from whole exome sequencing and gene panel analyses. In the field of androgenetics, significant progress was made mainly in the genetic diagnosis of extreme qualitative (terato- and asthenozoospermia) and quantitative semen phenotypes (azoospermia).

In this Special Issue, two reviews deal with qualitative alterations of spermatogenesis: one concerns sperm motility due to tail anomalies (asthenozoospermia) and the other focuses on a specific sperm head defect (globozoospermia) affecting sperm fertilizing ability (Touré et al. 2021; Celse 
et al. 2021). The spermatozoan is a unique cell with many highly specialized structural features. The flagellum is essential to allow spermatozoa to reach to the site of fertilization whereas the acrosome on top of the sperm head is essential for fertilizing the egg. A condition of extreme asthenozoospermia with near zero progressive sperm is defined as a distinct pathological entity called "Multiple Morphological Abnormalities of the sperm Flagellum" (MMAF) (Ben Khelifa et al. 2014). MMAF is associated with a severe disorganization of either axonemal or peri-axonemal structures. The review by Touré et al (2021) discusses extensively the latest findings concerning the 18 candidate genes for MMAF, whose recessive mutations account for up to $60 \%$ of cases. Many of the 18 encoded proteins had unknown functions at the time of their discovery. The comprehensive molecular characterization of these genes has provided novel insights into mammalian spermatogenesis and flagellum biogenesis and highlighted the fact that axonemal biogenesis/ structure of sperm flagella and cilia may require different proteins and mechanisms. In theory, the technique termed IntraCytoplasmic Sperm Injection (ICSI) should overcome the tail defect-related infertility given that spermatozoa is directly injected into the oocyte. However, it does not seem to be the case for a few MMAF gene mutations. For instance, centrosome defects lead to ICSI failure since this cellular component is also involved in the control of the first division after egg fertilization. On the other hand, the reason behind the negative impact of DNAH17 and CFAP65 mutationsaffecting the dynein arm and axoneme assembly, respectively - on the achievement or maintenance of pregnancy remains unexplained. Hence, future investigations on the genotype-phenotype correlation of different MMAF gene defects will have an important clinical impact also in terms of ICSI prognosis.

The second review dealing with qualitative defects of spermatogenesis focuses on globozoospermia, an autosomal recessive rare disease associated with the production of round-headed spermatozoa, lacking acrosin (Celse et al. 2021). The authors give a comprehensive overview of the literature and in addition present their original data on a genetic investigation performed in a large group of globozoospermic patients. They provide clear description about the clinical indications for genetic testing (i.e. subjects with $>50 \%$ of globozoospermic spermatozoa in the ejaculate) and about the methodological aspects. The major gene of globozoospermia remains DPY19L2, which is often deleted either in homozygosis or in heterozygosis due to the presence of deletion-predisposing repeated sequences at the margin of the gene. The study reports a positive correlation between the percentage of globozoospermic sperm in the ejaculate and the likelihood of finding a DPY19L deletion(s) or other mutations. The diagnostic impact of other known candidate genes is marginal but ongoing exome studies will likely identify novel genetic factors to be tested in DPY19L2negative subjects (Celse et al. 2021).

Four articles in this issue are devoted to specific genetic causes of azoospermia, the severest form of infertility, affecting $1 \%$ of men in the general population. Azoospermia is a constant feature of congenital Hypogonadotrophic Hypogonadism (cHH) owing to the missing action of FSH and LH on testicular function. Whilst only a relatively small percentage of infertile patients are affected by this disease, its diagnosis has major implications for patient management. In over $80 \%$ of $\mathrm{cHH}$ patients, spermatogenesis can be induced by hormonal treatment with the consequent induction of natural pregnancy and potential transmission of the trait. Two articles are dedicated to the genetic dissection of $\mathrm{cHH}$ and provide an excellent overview on the complexity and the many peculiarities of this rare disease (Cangiano et al. 2021; Butz et al. 2021). For instance, cHH only in part follows Mendelian laws of segregation and it represents one of the best proven examples of di/oligogenicity. This implies that genetic screening for $\mathrm{cHH}$ should be based on a NGS gene panel including a large set of candidate genes. Butz et al. (2021) provide useful clinical data on panel design and data interpretation through the comparison of different gene panels in terms of their diagnostic yield.

Post-testicular anomalies of the urogenital tract may lead to "obstructive azoospermia" and the congenital bilateral absence of vas deferens (CBAVD) is part of this etiological category. The role of CFTR gene mutations in this phenotype has been well known for more than 30 years, and CFTR screening provides the genetic diagnosis in up to $80 \%$ of cases. Bieth et al. (2021) provide a genetic update on CBAVD, introducing in the diagnostic flowchart also a novel X-linked gene (ADGRG2) which should be tested in CFTR-negative cases. In CBAVD patients, spermatogenesis is unaltered; hence, testicular sperm extraction (TESE) followed by ICSI will solve the infertility issue. This implies that a large part of the review is dedicated to the genetic counselling of the couple, highlighting the unusually high frequency of CFTR mutation carriers (heterozygous) in the Caucasian population (1:25) and the complexity of predicting the severity of the phenotype in the descendants.

The most frequent type of azoospermia is related to primary testicular failure, called also as "non-obstructive azoospermia" (NOA). Karyotype anomalies and the Y chromosome-linked AZF deletions account for up to $18 \%$ of NOA. The clinical relevance of these genetic tests is briefly presented in this special issue (Xavier et al. 2021; Kasak and Laan 2021). Whereas Y chromosome-linked deletions are well-known causes of impaired sperm production, our knowledge of the role of the other sex chromosome has been rather limited for a long time. Thanks to the studies performed in David Page's laboratory (Mueller et al. 2008, 2013; Skaletsky et al. 2003) it became clear that the X and Y 
chromosomes share common features: (1) both are enriched in genes exclusively or overexpressed in the testis; (2) both are enriched in repeated sequences which are substrates for deletion formation. Since both chromosomes occur in a single copy in the male genome, pathogenic mutations may have a direct phenotypic effect because of the lack of a second compensatory allele. Based on the above-described similarities, we hypothesized the existence of AZF-like region(s) on the $X$ chromosome as well (Krausz et al. 2012). However, array-CGH studies were unable to identify recurrently deleted regions, with the exception of one large deletion on Xq28 (CNV67) and an intragenic deletion in the testis-specific gene called TEX11 (Lo Giacco et al. 2014; Yatsenko et al. 2015). The review by Vockel et al. (2021) describes in detail CNV67, TEX11 and several other validated X-linked genetic defects related to different infertility phenotypes and highlights the difficulties in interpreting data due to striking evolutionary differences between mice and humans and to the complexity and highly repetitive structure of the $\mathrm{X}$ chromosome. A gene family called Cancer Testis Antigens-X (CTA-X) is still a mysterious group of genes, representing $10 \%$ of the total gene content on the $\mathrm{X}$ chromosome. In adulthood and in various physiological conditions, these genes are expressed exclusively in the testis, and can be aberrantly activated in various types of cancer. Although the biological function of these genes is unknown, their expression profile in spermatogonia suggests a potential role in cell proliferation. Hopefully, when spermatogonial cell cultures will become widely available, the exact role of CTA-X genes in spermatogenesis can be defined. In addition, novel $\mathrm{X}$-linked genetic factors are expected to be discovered by WES.

Thanks to whole exome-based investigations in NOA patients, the percentage of "idiopathic" forms of NOA (i.e. azoospermia with unknown etiology) is becoming progressively reduced. NOA is a clinical endpoint of a spectrum of alternative pathological processes and sub-phenotypes; therefore, it can be the consequence of Sertoli cell only syndrome, maturation arrest at different stages of spermatogenesis and an extreme quantitative defect called hypospermatogenesis (Krausz and Riera-Escamilla 2018). Based on the heterogenous testicular phenotype and the previously mentioned negative selective pressure on infertility-causing gene defects, we expect a high degree of locus heterogeneity in monogenic defects causing NOA.

A number of NOA genes, specifically those causing meiotic arrest, have been discovered and immediately validated thanks to data sharing between different laboratories and the members of the International Male Infertility Genomics Consortium (http://www.imigc.org) and the Genetics of Male Infertility Initiative (GEMINI) consortium ( http:// www.gemini.conradlab.org) (Kasak and Laan 2021; Xavier et al. 2021; Krausz et al. 2020; Capalbo et al. 2020). In this issue, we can read about mutations in three genes (TERB1, $T E R B 2$ and $N A J M I N$ ) that play a role in the tripartite meiotic telomere complex (MTC), which has been shown in mouse models to be necessary for completion of meiosis (SalasHuetos et al. 2021). Salas-Huetos and collaborators report recessive mutations in these genes and propose defects in TERB2 and NAJMIN as novel causes of meiotic arrest in human. Since two other very recent articles reported TERBI mutations in patients with meiotic arrest (Krausz et al. 2020; Alhathal et al. 2020), the Salas-Huetos et al. study (2021) contributes to the clinical upgrading of the gene-disease relationship between TERB 1 mutations and spermatocytic arrest.

A specific challenge in this field is how to conclude that the identified variants are causative, especially for non-loss of function mutations. The large majority of NOA patients are singleton, sporadic cases in their families; hence, a proper familial segregation and linkage analysis that is considered a key step to uncover inborn errors of Mendelian phenotypes (Posey et al. 2019) cannot be performed. With regard to this issue, Houston et al. (2021) propose an innovative pipeline starting from the filtering of human whole exome sequencing data in the context of male infertility combined with a subsequent high-resolution phenotyping of candidate male infertility mouse mutants. The authors point out the difficulty in interpreting missense variants and how knocking in missense mutations in the mouse can be a viable option thanks to CRISPR technologies. A thoughtful description is given on how to characterize mutant mouse models of male infertility and how it will help investigators to demonstrate a cause-effect relationship between a given mutation and the infertility phenotype. A novel approach to pinpoint the relationship between potential causal genetic variants of azoospermia and their effect on the complex cellular structure of spermatogenesis is proposed in the review by Soraggi et al. (2021). Technological developments have recently made it possible to perform single-cell RNA sequencing (scRNAseq) of all cell types in the testis. Genome sequencing in combination with scRNAseq allows one to connect potential pathogenic mutations directly to the testicular cell type where the effect is likely to be exerted. Insights are given about how scRNAseq data should be processed and interpreted to draw the correct conclusions.

The genetic diagnosis of NOA is not only useful for diagnostic purposes but it is also highly relevant for its multiple implications including prognosis for testicular sperm retrieval and implications for general health of the carrier and his descendants. In fact, many azoospermic men may now have their own biological children thanks to the combined approach of testicular biopsy followed by ICSI (Tournaye et al. 2017a). Various authors of this special issue have addressed the possible genetic link between altered spermatogenic function and a higher incidence of morbidity 
(including cancer) and lower life expectancy (Vockel et al. 2021; Kasak and Laan 2021; Xavier et al. 2021). For instance, a higher 'burden' of deletions, particularly on the $\mathrm{X}$ chromosome, in infertile men versus normozoospermic controls may be the expression of a generalized genomic instability, which may also lead to general health problems (Krausz et al. 2012; Tuettelmann et al. 2011; Lopes et al. 2013). In addition, genes encoding for proteins involved in DNA repair and apoptosis are relevant both to spermatogenesis (mitotic and meiotic processes) and cancer development; hence, their defect may lead to both pathological conditions (Kasak and Laan 2021). The growing evidence for shared genetic factors has repercussions for patient management, especially in view of long-term follow-up and prevention (Kasak and Laan 2021; Krausz et al. 2019).

Thanks to the wide diffusion of WES, we expect to find many novel genes involved in the various etiological categories of impaired male reproductive function. The joint efforts between the members of the above-mentioned international consortia have already allowed the immediate validation of a number of new genes. Among the missions of the International Male Infertility Genomics Consortium (IMIGC) is to promote data sharing between international research groups and to perform periodically a clinical validity assessment of candidate genes, to ensure a rapid translation of novel genetic findings into the diagnostic setting. Diagnosing a genetic cause of infertility in the era of in vitro fertilization has obvious clinical implications, not only for the reproductive health and general health of the patient but also for his children.

The field of molecular genetics of male infertility is currently witnessing its gold age as is testified by the content of this special issue. As far as the future of androgenetics in concerned, a major breakthrough is to be expected from ongoing consortia-based efforts allowing the analysis of several thousand well-characterized patients with unbiased genomics approaches together with the development of specific functional validation assays.

\section{References}

Alhathal N, Maddirevula S, Coskun S, Alali H, Assoum M, Morris T, Deek HA, Hamed SA, Alsuhaibani S, Mirdawi A, Ewida N, AlQahtani M, Ibrahim N, Abdulwahab F, Altaweel W, Dasouki MJ, Assiri A, Qabbaj W, Alkuraya FS (2020) A genomics approach to male infertility. Genet Med. https://doi.org/10.1038/s41436-0200916-0 (Epub ahead of print. PMID: 32719396)

Ben Khelifa M, Coutton C, Zouari R, Karaouzène T, Rendu J, Bidart M, Yassine S, Pierre V, Delaroche J, Hennebicq S, Grunwald D, Escalier D, Pernet-Gallay K, Jouk PS, Thierry-Mieg N, Touré A, Arnoult C, Ray PF (2014) Mutations in DNAH1, which encodes an inner arm heavy chain dynein, lead to male infertility from multiple morphological abnormalities of the sperm flagella. Am J Hum Genet 94:95-104. https://doi.org/10.1016/j.ajhg.2013.11.017 (PMID: 24360805)

Bieth E, Hamdi SM, Mieusset R (2021) Genetics of the congenital absence of the vas deferens. Hum Genet. https://doi. org/10.1007/s00439-020-02122-w (Epub ahead of print. PMID: 32025909)

Butz H, Nyírô G, Kurucz PA, Likó I, Patócs A (2021) Molecular genetic diagnostics of hypogonadotropic hypogonadism: from panel design towards result interpretation in clinical practice. Hum Genet. https://doi.org/10.1007/s00439-020-02148-0 (Epub ahead of print. PMID: 32222824)

Cangiano B, Swee DS, Quinton R, Bonomi M (2021) Genetics of congenital hypogonadotropic hypogonadism: peculiarities and phenotype of an oligogenic disease. Hum Genet. https://doi.org/10.1007/ s00439-020-02147-1 (Epub ahead of print. PMID: 32200437)

Capalbo A, Poli M, Riera-Escamilla A, Shukla V, Kudo Høffding M, Krausz C, Hoffmann ER, Simon C (2020) Preconception genome medicine: current state and future perspectives to improve infertility diagnosis and reproductive and health outcomes based on individual genomic data. Hum Reprod Update. https://doi. org/10.1093/humupd/dmaa044 (Epub ahead of print. PMID: 33197264)

Celse T, Cazin C, Mietton F, Martinez G, Martinez D, Thierry-Mieg N, Septier A, Guillemain C, Beurois J, Clergeau A, Mustapha SFB, Kharouf M, Zoghmar A, Chargui A, Papaxanthos A, Dorphin B, Foliguet B, Triki C, Sifer C, Lauton D, Tachdjian G, Schuler G, Lejeune H, Puechberty J, Bessonnat J, Pasquier L, Mery L, Poulain M, Chaabouni M, Sermondade N, Cabry R, Benbouhadja S, Veau S, Frapsauce C, Mitchell V, Achard V, Satre V, Hennebicq S, Zouari R, Arnoult C, Kherraf ZE, Coutton C, Ray PF (2021) Genetic analyses of a large cohort of infertile patients with globozoospermia, DPY19L2 still the main actor, GGN confirmed as a guest player. Hum Genet. https://doi.org/10.1007/s00439-02002229-0 (Epub ahead of print. PMID: 33108537)

Di Persio S, Saracino R, Fera S, Muciaccia B, Esposito V, Boitani C, Berloco BP, Nudo F, Spadetta G, Stefanini M, de Rooij DG, Vicini E (2017) Spermatogonial kinetics in humans. Development 144:3430-3439. https://doi.org/10.1242/dev.150284 (Epub 2017 Aug 21. PMID: 28827392)

Houston BJ, Conrad DF, O’Bryan MK (2021) A framework for highresolution phenotyping of candidate male infertility mutants: from human to mouse. Hum Genet. https://doi.org/10.1007/s0043 9-020-02159-x (Epub ahead of print. PMID: 32248361)

Kasak L, Laan M (2021) Monogenic causes of non-obstructive azoospermia: challenges, established knowledge, limitations and perspectives. Hum Genet. https://doi.org/10.1007/s00439-020-02112 -y (Epub ahead of print. PMID: 31955275)

Krausz C, Casamonti E (2017) Spermatogenic failure and the Y chromosome. Hum Genet 136:637-655. https://doi.org/10.1007/s0043 9-017-1793-8 (PMID: 28456834)

Krausz C, Riera-Escamilla A (2018) Genetics of male infertility. Nat Rev Urol 15:369-384. https://doi.org/10.1038/s41585-018-0003-3 (PMID: 29622783)

Krausz C, Giachini C, Lo Giacco D, Daguin F, Chianese C, Ars E, Ruiz-Castane E, Forti G, Rossi E (2012) High resolution X chromosome-specific array-CGH detects new CNVs in infertile males. PLoS ONE 7:44887. https://doi.org/10.1371/journal.pone.00448 87 (PMID: 23056185)

Krausz C, Hoefsloot L, Simoni M, Tüttelmann F, European Academy of Andrology; European Molecular Genetics Quality Network (2014) EAA/EMQN best practice guidelines for molecular diagnosis of Y-chromosomal microdeletions: state-of-the-art 2013. Andrology 2:5-19. https://doi.org/10.1111/j.2047-2927.2013.00173.x (PMID: 24357628) 
Krausz C, Riera-Escamilla A, Chianese C, Moreno-Mendoza D, Ars E, Rajmil O, Pujol R, Bogliolo M, Blanco I, Rodríguez I, Badell I, Ruiz-Castañé E, Surrallés J (2019) From exome analysis in idiopathic azoospermia to the identification of a high-risk subgroup for occult Fanconi anemia. Genet Med 21:189-194. https://doi. org/10.1038/s41436-018-0037-1 (PMID: 29904161)

Krausz C, Riera-Escamilla A, Moreno-Mendoza D, Holleman K, Cioppi F, Algaba F, Pybus M, Friedrich C, Wyrwoll MJ, Casamonti E, Pietroforte S, Nagirnaja L, Lopes AM, Kliesch S, Pilatz A, Carrell DT, Conrad DF, Ars E, Ruiz-Castañé E, Aston KI, Baarends WM, Tüttelmann F (2020) Genetic dissection of spermatogenic arrest through exome analysis: clinical implications for the management of azoospermic men. Genet Med. https ://doi.org/10.1038/s41436-020-0907-1 (Epub ahead of print. PMID: 32741963)

Lo Giacco D, Chianese C, Ars E, Ruiz-Castañé E, Forti G, Krausz C (2014) Recurrent X chromosome-linked deletions: discovery of new genetic factors in male infertility. J Med Genet 51:340344. https://doi.org/10.1136/jmedgenet-2013-101988 (PMID: 24421283)

Lopes AM, Aston KI, Thompson E, Carvalho F, Gonçalves J, Huang N, Matthiesen R, Noordam MJ, Quintela I, Ramu A, Seabra C, Wilfert AB, Dai J, Downie JM, Fernandes S, Guo X, Sha J, Amorim A, Barros A, Carracedo A, Hu Z, Hurles ME, Moskovtsev S, Ober C, Paduch DA, Schiffman JD, Schlegel PN, Sousa M, Carrell DT, Conrad DF (2013) Human spermatogenic failure purges deleterious mutation load from the autosomes and both sex chromosomes, including the gene DMRT1. PLoS Genet 9:e1003349. https://doi. org/10.1371/journal.pgen.1003349 (PMID: 23555275)

Mueller JL, Mahadevaiah SK, Park PJ, Warburton PE, Page DC, Turner JM (2008) The mouse X chromosome is enriched for multicopy testis genes showing postmeiotic expression. Nat Genet 40:794799. https://doi.org/10.1038/ng.126

Mueller JL, Skaletsky H, Brown LG, Zaghlul S, Rock S, Graves T, Auger K, Warren WC, Wilson RK, Page DC (2013) Independent specialization of the human and mouse $\mathrm{X}$ chromosomes for the male germ line. Nat Genet 45:1083-1087. https://doi.org/10.1038/ ng. 2705

Posey JE, O'Donnell-Luria AH, Chong JX, Harel T, Jhangiani SN, Coban Akdemir ZH, Buyske S, Pehlivan D, Carvalho CMB, Baxter S, Sobreira N, Liu P, Wu N, Rosenfeld JA, Kumar S, Avramopoulos D, White JJ, Doheny KF, Witmer PD, Boehm C, Sutton VR, Muzny DM, Boerwinkle E, Günel M, Nickerson DA, Mane S, MacArthur DG, Gibbs RA, Hamosh A, Lifton RP, Matise TC, Rehm HL, Gerstein M, Bamshad MJ, Valle D, Lupski JR, Centers for Mendelian Genomics (2019) Insights into genetics, human biology and disease gleaned from family based genomic studies. Genet Med 21:798-812. https://doi.org/10.1038/s41436-0180408-7 (PMID: 30655598)

Salas-Huetos A, Tüttelmann F, Wyrwoll MJ, Kliesch S, Lopes AM, Conçalves J, Boyden SE, Wöste M, Hotaling JM, GEMINI Consortium, Nagirnaja L, Conrad DF, Carrell DT, Aston KI (2021) Disruption of human meiotic telomere complex genes TERB1, TERB 2 and MAJIN in men with non-obstructive azoospermia. Hum Genet. https://doi.org/10.1007/s00439-020-02236-1 (Epub ahead of print. PMID: 33211200)

Skaletsky H, Kuroda-Kawaguchi T, Minx PJ, Cordum HS, Hillier L, Brown LG, Repping S, Pyntikova T, Ali J, Bieri T, Chinwalla A,
Delehaunty A, Delehaunty K, Du H, Fewell G, Fulton L, Fulton R, Graves T, Hou SF, Latrielle P, Leonard S, Mardis E, Maupin R, McPherson J, Miner T, Nash W, Nguyen C, Ozersky P, Pepin K, Rock S, Rohlfing T, Scott K, Schultz B, Strong C, Tin-Wollam A, Yang SP, Waterston RH, Wilson RK, Rozen S, Page DC (2003) The male specific region of the human $\mathrm{Y}$ chromosome is a mosaic of discrete sequence classes. Nature 423:825-837. https://doi. org/10.1038/nature01722

Soraggi S, Riera M, Rajpert-De Meyts E, Schierup MH, Almstrup K (2021) Evaluating genetic causes of azoospermia: What can we learn from a complex cellular structure and single-cell transcriptomics of the human testis? Hum Genet. https://doi.org/10.1007/ s00439-020-02116-8 (Epub ahead of print. PMID: 31950241)

Touré A, Martinez G, Kherraf ZE, Cazin C, Beurois J, Arnoult C, Ray PF, Coutton C (2021) The genetic architecture of morphological abnormalities of the sperm tail. Hum Genet. https://doi. org/10.1007/s00439-020-02113-x (Epub ahead of print. PMID: 31950240)

Tournaye H, Krausz C, Oates RD (2017a) Concepts in diagnosis and therapy for male reproductive impairment. Lancet Diabetes Endocrinol 5:554-564. https://doi.org/10.1016/S2213-8587(16)30043 -2 (PMID: 27395770)

Tournaye H, Krausz C, Oates RD (2017b) Novel concepts in the aetiology of male reproductive impairment. Lancet Diabetes Endocrinol 5:544-553. https://doi.org/10.1016/S2213-8587(16)30040 -7 (Epub 2016 Jul 7 PMID: 27395771)

Tüttelmann F, Simoni M, Kliesch S, Ledig S, Dworniczak B, Wieacker $P$, Röpke A (2011) Copy number variants in patients with severe oligozoospermia and Sertoli-cell-only syndrome. PLoS ONE 6:e19426. https://doi.org/10.1371/journal.pone.0019426 (PMID: 21559371)

Vockel M, Riera-Escamilla A, Tüttelmann F, Krausz C (2021) The $\mathrm{X}$ chromosome and male infertility. Hum Genet. https://doi. org/10.1007/s00439-019-02101-w (Epub ahead of print. PMID: 31875237)

Vogt PH, Edelmann A, Kirsch S, Henegariu O, Hirschmann P, Kiesewetter F, Köhn FM, Schill WB, Farah S, Ramos C, Hartmann M, Hartschuh W, Meschede D, Behre HM, Castel A, Nieschlag E, Weidner W, Gröne HJ, Jung A, Engel W, Haidl G (1996) Human Y chromosome azoospermia factors (AZF) mapped to different subregions in Yq11. Hum Mol Genet 5:933-943. https ://doi.org/10.1093/hmg/5.7.933 (PMID: 8817327)

Xavier MJ, Salas-Huetos A, Oud MS, Aston KI, Veltman JA (2021) Disease gene discovery in male infertility: past, present and future. Hum Genet. https://doi.org/10.1007/s00439-020-02202-x (Epub ahead of print. PMID: 32638125)

Yatsenko AN, Georgiadis AP, Röpke A, Berman AJ, Jaffe T, Olszewska M, Westernströer B, Sanfilippo J, Kurpisz M, Rajkovic A, Yatsenko SA, Kliesch S, Schlatt S, Tüttelmann F (2015) X-linked TEX11 mutations, meiotic arrest, and azoospermia in infertile men. N Engl J Med 372:2097-2107. https://doi.org/10.1056/ NEJMoa1406192 (PMID: 25970010)

Publisher's Note Springer Nature remains neutral with regard to jurisdictional claims in published maps and institutional affiliations. 